\title{
SESAME OIL MITIGATES INITIATION STAGE OF DIETHYNITROSAMINE HEPATOCARCINOGENESIS IN RATS
}

\author{
AbdAllah A. Mokh ${ }^{1}$, Doaa H. Abdelhady ${ }^{1}$, Emad W. Ghazy ${ }^{1}$, Hadeer Aboumosalem ${ }^{1 *}$, \\ Wael M.Goda ${ }^{2}$
}

${ }^{1}$ Faculty of Veterinary Medicine, Department of Clinical Pathology, Kafrelsheikh University, ${ }^{2}$ Faculty of Veterinary Medicine, Department of Clinical Pathology, Damanhour University, Egypt

${ }^{*}$ Corresponding author, E-mail: hadeeraboumosalem@gmail.com

\begin{abstract}
Diethylnitrosamine (DEN) induced hepatocarcinogenesis in experimental animals through triggering reactive oxygen species (ROS) release and subsequent induction of oxidative stress dependant liver damage. This study was conducted to estimate the protective role of sesame oil (SO) in the initial phase of DEN induced hepatocarcinogenesis. Forty five male Wistar rats were randomly divided into five groups groups ( $n=9$ each). In the first group (control), rats were orally administrated normal saline. Rats of second group (DEN) were intraperitoneally (i.p) injected with a single dose of $(200 \mathrm{mg} / \mathrm{kg}$ body weight, DEN) at the $8^{\text {th }}$ day of the experiment. The third, fourth, fifth groups orally administrated SO at a dose $(2.5,5,10 \mathrm{~mL} / \mathrm{kg} \mathrm{b.w)}$, respectively 1 week before i.p injection of DEN and continued for 4 successive weeks. DEN- induced hepatotoxicity as detected by normocytic normochromic anemia with marked increase in white blood cells and significant increase in hepatic damage enzymatic markers (alanine transaminase (ALT), aspartate aminotransferase (AST), y-glutamyl Transferase ( $\mathrm{YGT}$ ) and alkaline phosphatase (ALP)) with significant decrease in serum total protein. Hepatic malondialdehyde (MDA) was increased significantly while hepatic antioxidant biomarkers superoxide dismutase (SOD), catalase (CAT) and hepatic reduced glutathione (GSH) were significantly decreased. Histological examination of hepatic tissue of DEN treated rats proved centrolobular necrosis associated with bile duct and oval cell proliferation. This was accompanied with over expression of CYP2E1 and down regulation in BAX gene expression in liver. Administration of SO minimized the harmful effects of DEN on hematological, biochemical, antioxidant and histopathological parameter as well as on gene expression. The degree of improvement was in dose dependant manner. Our findings revealed that SO supplementation can mitigate the toxic effects of DEN via their potent antioxidant and free radical-scavenging activities.
\end{abstract}

Key words: diethylnitrosamine, sesame oil, antioxidant, gene expression, rats

\section{Introduction}

Liver cancer considers one of the most frequent causes of death. Hepatocellular carcinoma (HCC) is a malicious tumor of liver cell originating from hepatocyte and considered as 
the most common third cause of cancer death worldwide $(1,2)$. The main risk factors in liver cancer include hepatitis $\mathrm{C}$ virus, feed additives as (BHA BHT, nitrates/nitrites), mycotoxins, air and water pollutants (3). In Egypt, The prevalence of liver cancer has been growing in latest years (4).

Nitrosamines are potent environmental carcinogens because of their mutagenic and carcinogenic abilities. Nitrosamines found in water, industrial product, tobacco, cured cheese and smoked meats (5). Diethylnitrosamine (DEN) is commonly used to instigate hepatocellular carcinoma in experimental rat models $(6,7)$ probably through induction of oxidative stress, resulting in liver damage with increased deleterious free radicals formation (8). Chemoprevention may help to decrease the incidence or severity of carcinogenic insult. They can be used as approaches for liver cancer treatment with less toxic effects.

Sesame oil (SO) extracted from Sesamum indicum seeds which has phenolic lignans as sesamol, sesamin, sesamolin and tocopherol (vitamin E) all of which give sesame oil the significant free radical-scavenging ability (9). Sesame oil has the ability to minimize ROS production and lipid peroxidation in various animal model through its antioxidant ability (10). Thus, the current work aimed to estimate the hepatoprotective effect of sesame oil on initial stage of HCC induced by DEN in rat models.

\section{Materials and methods}

\section{Preparation of DEN and sesame oil}

DEN (purcashed from Sigma Aldrich) was dissolved in normal saline. Sesame oil was obtained from Harraz Company (Cairo, Egypt $100 \%$ pure) in a solution form, given at different concentrations $(2.5,5,10 \mathrm{ml} / \mathrm{kg} \mathrm{b.w})$ by stomach tube according to animal body weight.

\section{Animals}

Forty-five healthy male Wistar rats (weighing $90 \pm 20 \mathrm{~g} / \mathrm{rat}$ and at age of 1 month old) were obtained from the Alexandria Organization for Biological Products. The rats were housed in metallic cages with thermally controlled tem- perature ranged from 22 to $25{ }^{\circ} \mathrm{C}$, relative humidity $50-60 \%$, with $12 \mathrm{~h}$ photoperiods and $12 \mathrm{~h}$ dark. During the entire period of study, the rats were provided with a semi-purified basal diet and water ad libitum. The experiment protocol followed the Guide for the Care and Use of Laboratory Animals at Kafrelsheikh University. All safety measures had been taken to minimize animal stress.

\section{Experimental design}

After two weeks acclimatization period, random classification of rat into 5 different equal groups (9/each) was done. Rats in the $1^{\text {st }}$ group were kept as control and were only given normal saline by gastric intubation during the whole period of the experiment. A single ip injection of normal saline was also given to these rats at the $8^{\text {th }}$ day of the experiment to initiate hepatocarcinogenesis (11). Rats of the $2^{\text {nd }}$ group (DEN) were i.p injected with a single dose of DEN (200 mg/kg b.w) at the $8^{\text {th }}$ day of the experiment (11). The $3^{\text {rd }}$ group rats orally administrated sesame oil $(2.5 \mathrm{~mL} / \mathrm{kg}$ b.w $) 1$ week before i.p injection of DEN (at the first day of the experiment) and continued for 4 successive weeks. The $4^{\text {th }}$ group orally received sesame oil at a dose of $(5 \mathrm{~mL} / \mathrm{kg} \mathrm{b} . \mathrm{w}) 1$ week before i.p injection of DEN (at the first day of the experiment) and continued for 4 successive weeks (10). The $5^{\text {th }}$ group received sesame oil at a dose of $(10 \mathrm{~mL} / \mathrm{kg} \mathrm{b.w}$, orally) 1 week before i.p injection of DEN (at the first day of the experiment) and continued for 4 successive weeks (12).

\section{Blood and liver sampling}

Blood samples were collected from rats eyes by retro-orbital venus plexus bleeding under effect of mild ether anesthesia by using of clean capillary tubes and immediately grouped into two groups the first with anticoagulant for hematological parameters determination, the second group without anticoagulant for serum biochemical estimation. Later, rats were slaughtered and livers were rapidly removed then trimmed from excess tissues and washed by normal saline and distilled water, cut apart into three parts; The $1^{\text {st }}$ part was cut into slices and 
directly put in liquid nitrogen, then stored at-80 ${ }^{\circ} \mathrm{C}$ for molecular analysis. The $2^{\text {nd }}$ portion used to prepare tissue homogenate for antioxidant examination as previously described (13). The last portion was directly put in $10 \%$ formalin for histopathological analysis.

\section{Hematological examination}

Blood samples collected in tubes coated with EDTA (1mg/ml blood) were used for measuring of complete blood count (RBCs, Hb, PCV, MCV, MCHC, WBCs, and platelets count) using exigoautomated cell counter (Exigo BM800, USA)

\section{Biochemical parameters}

The serum level of (ALT) and (AST) enzymes were kinetically determined as previously described (14), while the serum level of $(\gamma \mathrm{GT})$ and(ALP) enzymes were Calorimetrically estimated by (15). Serum total protein and glucose were calorimetrically detected as previously detailed $(16,17)$. MDA level and activities of catalase, SOD and GSH were determined in liver homogenate as method described by (18-22).

\section{Histopathological analysis}

Liver tissue specimens were preserved in $10 \%$ neutral formalin, fixed in paraffin, sectioned and stained by H\&E (23).

\section{Molecular investigation of BAX and CYP2E1 genes}

Total RNA was extracted from liver with Trizol reagent (total RNA isolation reagent, INTRON Biotechnology, Inc). Complementary DNA (cDNA) was synthesized using cDNA synthesis kits as previously described (24). PCR tubes containing SYPR green master mix (Enzynomic company, Cat number RT500), cDNA, primers (Table1) and RNase free water were inserted in BIoRad IQ2 real time thermal cycler. $\beta$ - actin was used as a housekeeping gene. Thermal cycling conditions were: incubation at $94{ }^{\circ} \mathrm{C}$ for $15 \mathrm{~min}$ then $94{ }^{\circ} \mathrm{C}$ for $15 \mathrm{~s}(40$ cycles) followed by $60^{\circ} \mathrm{C}$ for $30 \mathrm{~s}$ and $70{ }^{\circ} \mathrm{C}$ for 30 s. The data reported at extension step. Melting curve analysis used to determine specificity of PCR products. IQ5 software was used to detect amplification curves and $\mathrm{Ct}$ values. Gene expression variation of different samples determined through comparing between the $\mathrm{Ct}$ val-

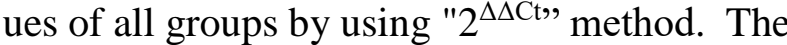
PCR products were confirmed by using $1.5 \%$ agarose gel.

\section{Data statistical analysis}

Graph pad prism version 5.0 was used to analyze the resulted data. Differences in values were analyzed by one-way analysis of variance (ANOVA), then Tukey's-compare all pairs of columns. All data were exposed as mean \pm standard error of the mean (SEM) with citation of significance level at $\mathrm{p}<0.05$.

\section{Results}

\section{Hematological finding}

Data explored in table (2) showed deleterious impacts of (DEN) and the ameliorative effects of Sesame oil on the erythrogram. A significant decrease in hematological parameters (RBCs, Hb, PCV and platelets) without significant change in the values of (MCV, $\mathrm{MCH}$ and $\mathrm{MCHC}$ ) was noticed in DEN treated group as compared to the control group. Opposing to these results WBCs count was significantly increased. SO treated group showed a marked ( $P$ $\leq 0.05)$ decrease in hematological parameters (RBCs, Hb, PCV and platelets) as compared to DEN-treated group, but with a significant $(P \leq$ $0.05)$ decrease in WBCs count.

\section{Serum Biochemical assays}

Data demonstrated in (Fig. 1A) showed toxic effects of DEN and the protective role of sesame oil on serum biochemical measurements. Group II (DEN) showed significant increases in the activity of hepatic damage enzymatic markers (ALT, AST, ALP, $\gamma$ GT) and serum glucose when compared with the control group. Group III, IV, V which supplied by sesame oil and (DEN) showing significant decrease in the activity of serum liver function marker enzymes (AST, ALT, ALP, $\gamma \mathrm{GT}$ ) and serum glucose when compared with the DEN group. The degree of improvement was in dose dependant manner. 
Data illustrated in table (2) showed deleterious effects of (DEN) and the ameliorative effects of sesame oil on Serum proteins. Group II (DEN) showed significant decreases in total proteins, albumin and globulins concentration when compared with control group. Group III, IV, V which supplied by sesame oil and DEN showing significant increase in total proteins, albumin and globulins concentration when compared with DEN group.

Data demonstrated in (Fig. 2) revealed the harmful effects of DEN as well as the challenge effects of Sesame oil on lipid peroxidation and antioxidant biomarkers. Group II (DEN) showed significant increase in hepatic MDA content, while liver CAT, GSH, and SOD activities were statically decreased when compared with control group. Group III, IV, V (DEN -SO) showed significant decreases in hepatic MDA content but liver CAT, GSH, SOD activities had increased markedly in comparing to DEN group.

\section{Histopathological finding}

Effect of DEN and Sesame oil on histopathological features of liver is presented in (Fig. 3). Histological examination of the hepatic tissue sections of control negative rats revealed normal hepatocellular architecture mainly consisting of normal hepatocytes with normal cytoplasm and small uniform vesicular-shaped nuclei which arranged in a radial pattern around the central vein of the hepatic lobules (Fig. 3A). Liver of control positive animal (DEN) revealed centrolobular necrosis associated with severe ballooning of hepatocytes. Moreover, severe ballooning of hepatocytes were associated with bile duct and oval cell proliferation (Fig. 3B). Liver of diseased animal treated with (2.5 ml Sesame oil) showed decreased hepatic vacuolation, bile duct hyperplasia and centrolobular necrosis (Fig. 3C). The fourth and fifth groups treated with $(5-10 \mathrm{ml}$ sesame oil) respectively, showing reduction of hepatic vacuolation with subsequent marked reduction the altered hepatocytes as well as the number of oval cells and the necrobiotic changes associated with DEN treatment appearing the hepatic tissues mostly within normal limits (Fig.3D, E), respectively.

\section{Molecular analysis}

The expression of $C Y P 2 E 1$ and $B A X$ genes was determined by Real time PCR that reveals the transcription levels changes of these genes in liver of rats after i.p injection of DEN alone or in combination with Sesame oil in three doses $(2.5,5,10 \mathrm{ml} / \mathrm{kg}$ b.w). DEN injection showed marked $(\mathrm{P} \leq 0.05)$ increase in $C Y P 2 E 1$ gene expression and significant decrease in $B A X$ gene expression in comparison with the control, while supplying of Sesame oil before DEN injection at a dose of $(2.5,5,10 \mathrm{ml} / \mathrm{kg}$ b.w) decreased the $C Y P 2 E 1$ gene expression and increased the expression of $B A X$ gene when compared with animals treated with DEN only as showed in (Fig. 4). The degree of improvement was dose dependent.

Table 1: Primers used in qPCR

\begin{tabular}{ll}
\hline Gene & $\begin{array}{l}\text { Primer sequence } \\
\left(5^{\prime}-3^{\prime}\right)\end{array}$ \\
\hline Rat 3 -actin & F 5'-TCCTCCTGAGCGCAAGTACTCT -3' \\
& R 5'-GCTCAGTAACAGTCCGCCTAGAA -3' \\
BAX & F 5'-CACCAGCTCTGAACAGATCATGA -3' \\
& R 5'-TCAGCCCATCTTCTTCCAGATGGT -3' \\
CYP2E1 & F 5'-CTCCTCGTCATATCCATCTG -3' \\
& R 5'-GCAGCCAATCAGAAATGTGG -3' \\
\hline
\end{tabular}


Table 2: The impact of SO supplementation against DEN on hematological parameters and Serum protein profile.

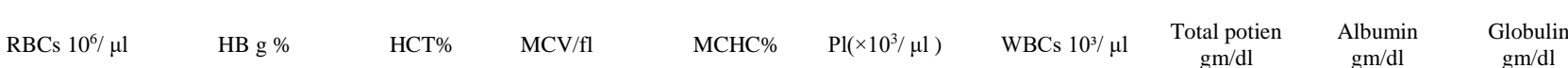

\begin{tabular}{|c|c|c|c|c|c|c|c|c|c|c|}
\hline Control & $6.9 \pm 0.10^{\mathrm{a}}$ & $13.4 \pm 0.36^{\mathrm{a}}$ & $46.6 \pm 1.14^{\mathrm{a}}$ & $66.9 \pm 1.63$ & $28.8 \pm 0.40$ & $714.8 \pm 6.5^{\mathrm{a}}$ & $10.2 \pm 1.12^{\mathrm{dc}}$ & $6.86 \pm 0.1^{\mathrm{a}}$ & $\begin{array}{l}3.86 \pm \\
0.08^{\mathrm{a}}\end{array}$ & $3 \pm 0.05^{\mathrm{a}}$ \\
\hline DEN & $5.9 \pm 0.05^{\mathrm{b}}$ & $10.3 \pm 0.04^{\mathrm{b}}$ & $36.9 \pm 0.10^{b}$ & $62.2 \pm 0.67$ & $27.8 \pm 0.13$ & $303.8 \pm 8.5^{\mathrm{d}}$ & $24.0 \pm 0.85^{\mathrm{a}}$ & $5.14 \pm 0.12^{\mathrm{c}}$ & $3 \pm 0.07^{\mathrm{c}}$ & $2.28 \pm 0.14^{\mathrm{b}}$ \\
\hline $\begin{array}{l}\text { DEN+ } \\
\text { Sesame oil } \\
(2.5 \mathrm{ml} / \mathrm{kg})\end{array}$ & $7.3 \pm 0.31^{\mathrm{a}}$ & $13.7 \pm 0.10^{\mathrm{a}}$ & $48.3 \pm 0.98^{\mathrm{a}}$ & $64.9 \pm 0.31$ & $28.7 \pm 0.36$ & $455.8 \pm 5.3^{\mathrm{c}}$ & $20.5 \pm 0.51^{\mathrm{ab}}$ & $6.1 \pm 0.08^{b}$ & $3.4 \pm 0.07^{\mathrm{b}}$ & $2.78 \pm 0.03^{\mathrm{a}}$ \\
\hline $\begin{array}{l}\text { DEN+ } \\
\text { Sesame oil ( } 5 \\
\mathrm{ml} / \mathrm{kg})\end{array}$ & $7.0 \pm 0.21^{\mathrm{a}}$ & $13.0 \pm 0.26^{\mathrm{a}}$ & $47.1 \pm 0.66^{\mathrm{a}}$ & $67.4 \pm 1.72$ & $27.6 \pm 0.23$ & $571.2 \pm 4.6^{\mathrm{b}}$ & $14.8 \pm 0.62^{\mathrm{c}}$ & $6.58 \pm 0.03^{\mathrm{a}}$ & $\begin{array}{l}3.66 \pm \\
0.04^{\mathrm{ba}}\end{array}$ & $2.92 \pm 0.02^{\mathrm{a}}$ \\
\hline $\begin{array}{l}\text { DEN+ } \\
\text { Sesame oil } \\
(10 \mathrm{ml} / \mathrm{kg})\end{array}$ & $7.2 \pm 0.10^{\mathrm{a}}$ & $13.5 \pm 0.18^{\mathrm{a}}$ & $48.0 \pm 1.32^{\mathrm{a}}$ & $66.4 \pm 1.33$ & $27.7 \pm 0.61$ & $700.2 \pm 3.2^{\mathrm{a}}$ & $12.5 \pm 1.10^{\mathrm{c}}$ & $6.7 \pm 0.05^{\mathrm{a}}$ & $3.7 \pm 0.07^{\mathrm{a}}$ & $3 \pm 0.1^{\mathrm{a}}$ \\
\hline
\end{tabular}

Values are means \pm standard error. $(n=9)$ Mean values with different letters at the same column differ significantly at ( $\mathrm{p} \leq 0.05$ ). RBCs: red blood cells, Hb: hemoglobin, HCT\%: hematocrite, MCV: mean corpuscular volume, MCHC: mean corpuscular hemoglobin concentration, WBCs: white blood cells, Pl: platelets.
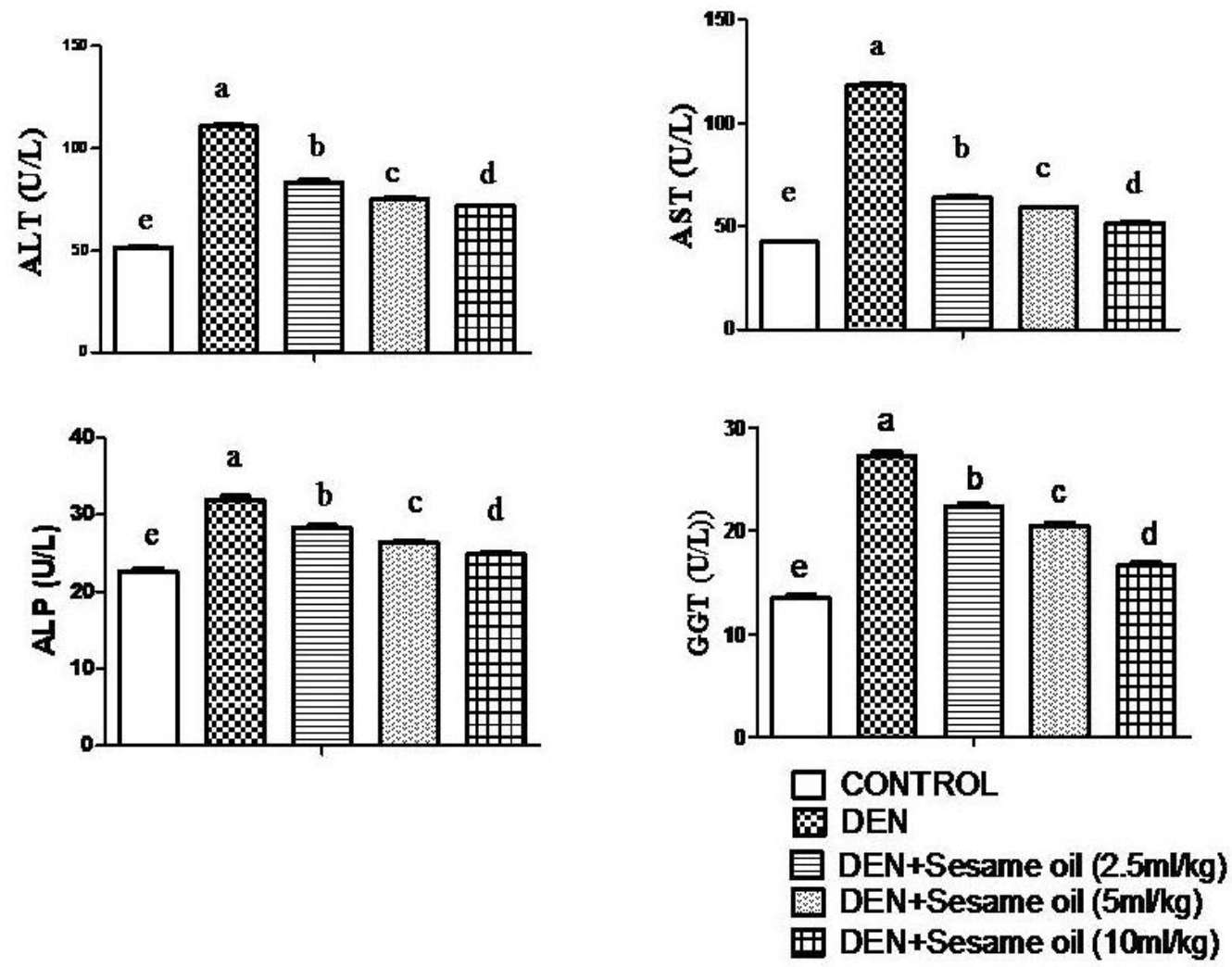

Figure 1: Effect of different concentrations of sesame oil on serum levels of liver enzymes (ALT, AST, ALP, GGT) of DEN-intoxicated rats. Values are means \pm standard error. ( $n=9)$. Mean values with different letters in each graph significantly differ at $(\mathrm{p} \leq 0.05)$ 

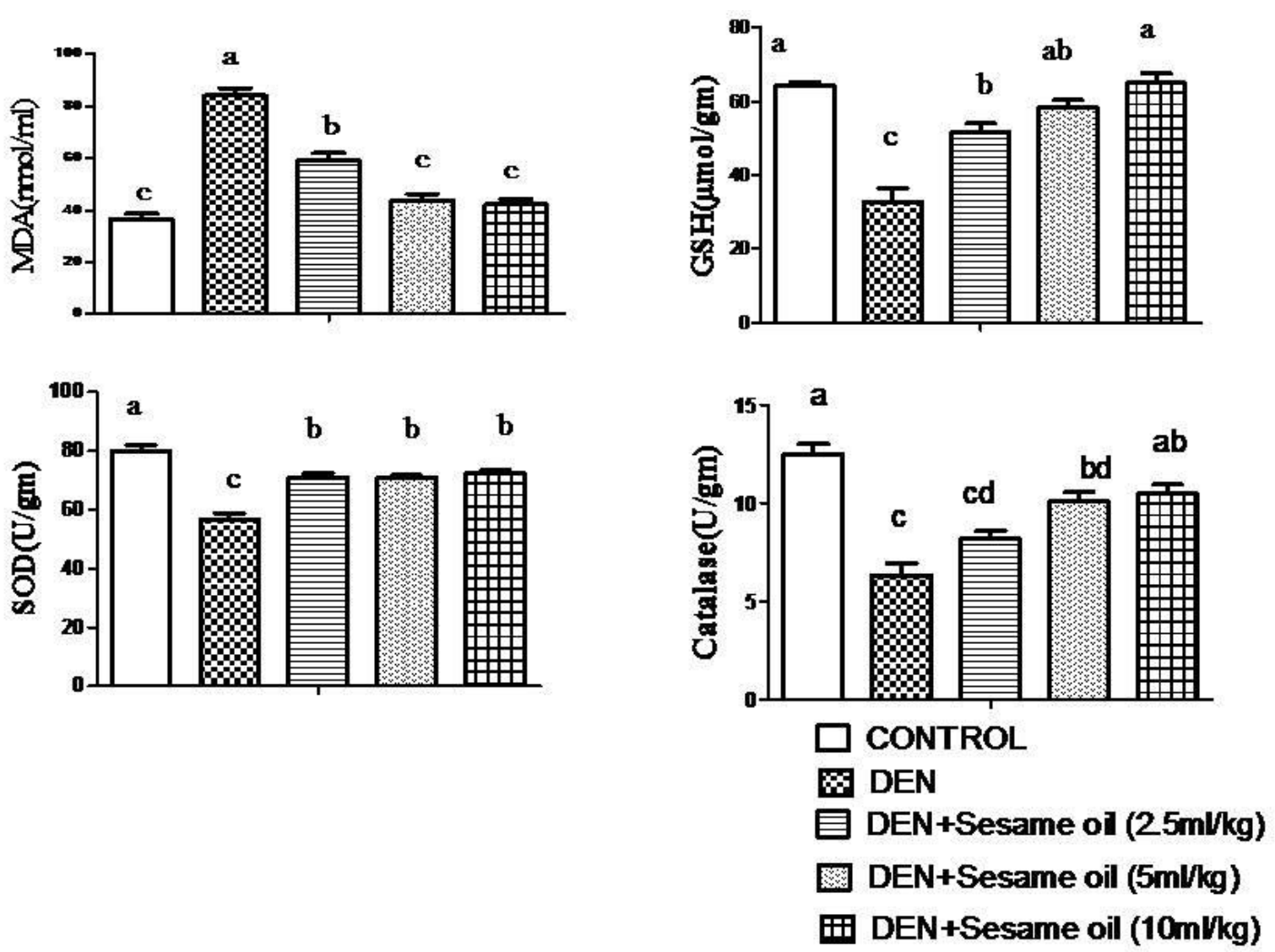

Figure 2: Effect of different concentrations of sesame oil on hepatic level of lipid peroxidation marker MDA, and endogenous antioxidants (GSH, SOD, CAT) of DEN-intoxicated rats. Values are means \pm standard error. $(n=9)$. Mean values with different letters in each graph significantly differ at $(p \leq 0.05)$
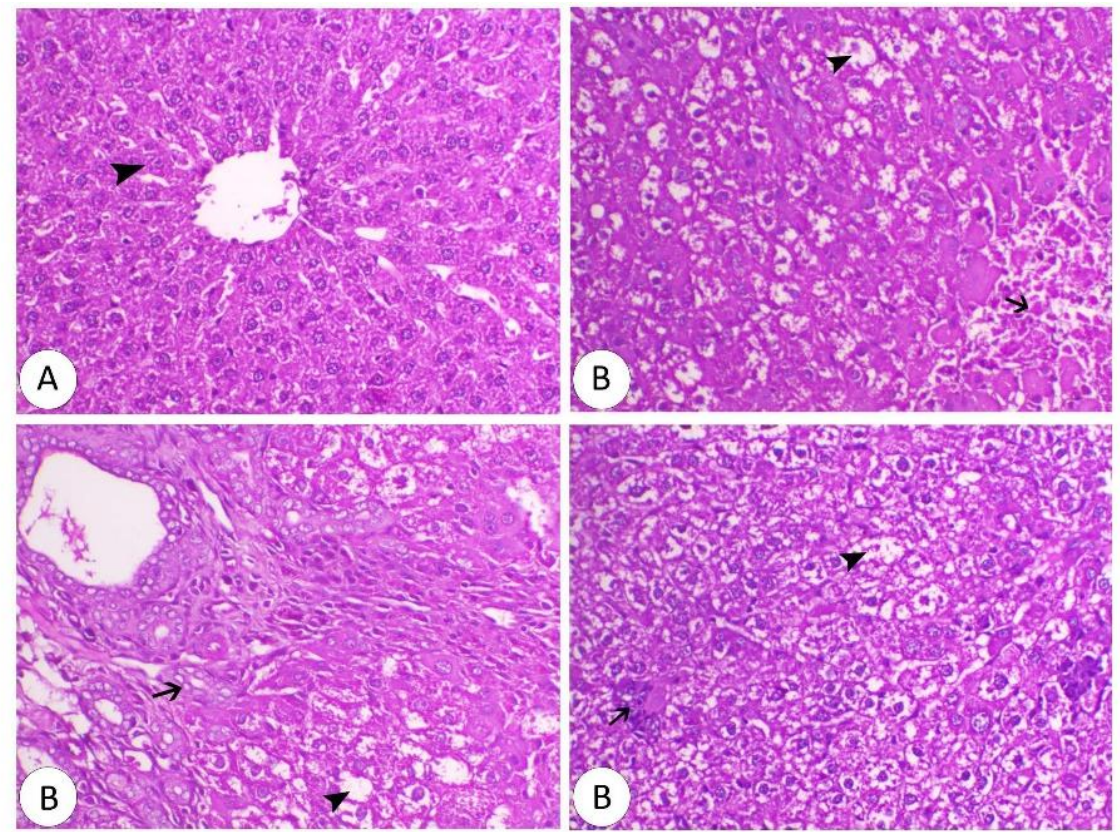

Figure 3: A. Liver of control animal showing normal hepatocytes arranged in cords around the central vein, H\&E, X 200. B. Liver of control positive animal showing centrolobular necrosis (arrows) associated with severe ballooning of hepatocytes (arrowheads), H\&E, X20 

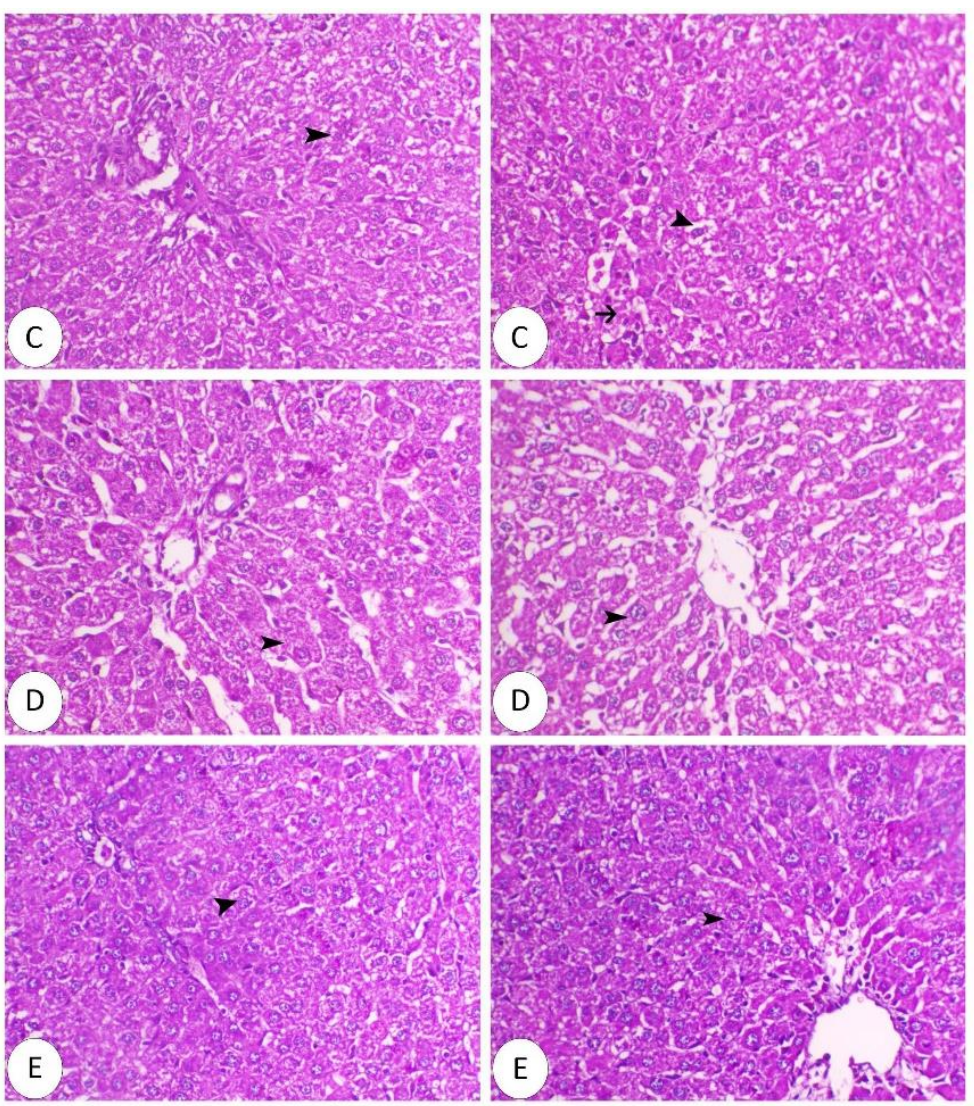

Fig.3. C. Liver of animal treated with DENA and Sesame oil $(2.5 \mathrm{ml})$ showing decrease hepatic vacuolation (arrowhead) and centrolobular necrosis (arrow). D. Liver of animal treated with DENA and Sesame oil (5 $\mathrm{ml}$ ) showing marked decrease hepatic vacuolation (arrowhead). E. Liver of animal treated with DENA and Sesame oil $(10 \mathrm{ml})$ showing significant decrease hepatic vacuolation (arrowhead). H\&E, X 200
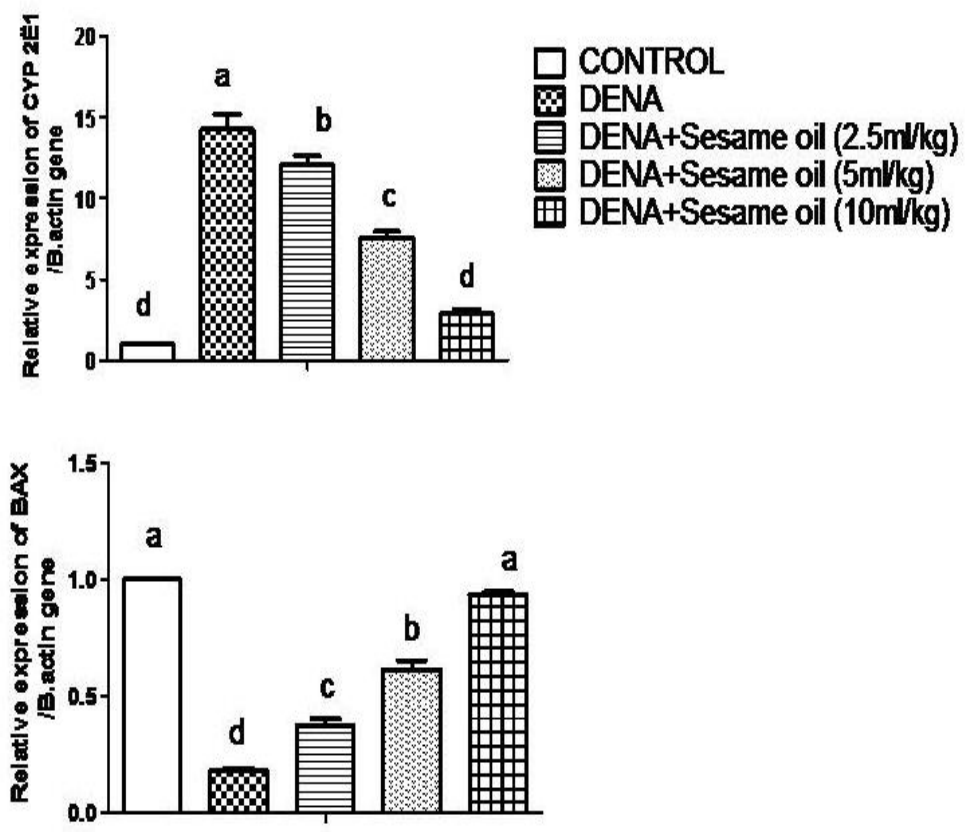

Figure 4: Effect of different concentrations of sesame oil on relative expression of $C Y P 2 E 1$ and $B A X$ genes in liver of DEN-intoxicated rats. Values are means \pm standard error. $(n=9)$. Mean values with different letters in each graph significantly differ at $(\mathrm{p} \leq 0.05)$. 


\section{Discussion}

T Hepatocellular carcinoma induced by several factors such as food supplement(25), endogenous or environmental stimuli (26). It happens stepwise through initial stage alterations, proliferation resulting in malignant transformation (27). DEN could be metabolized by cytochrome $\mathrm{P} 450$ to produce active ethyl radical, which can interact with DNA causing mutagenicity and consequent carcinogenesis $(28,29)$. Research on plants helped in the detection of compounds (30)with antitumor activity from non-traditionally useful plants that clinically used as effective drugs(31). The current study has been initiated to investigate whether sesame oil supplementation could inhibit the initiation stage of hepaticcarcinogenesis induced by DEN in rats.

Hematopoietic system is a very sensitive systems to estimate the danger impacts of drugs and toxins on our health (32). The current work revealed that i.p injection of DEN caused marked bad effect on the eyrthrogram of DEN rats. SO pretreatment had improved the disturbances of hematological parameters caused by DEN in an effective manner. The damaging consequences of DEN on hemogram was proved by significant reduction in $\mathrm{RBCs}, \mathrm{Hb} \%$, HCT and platelets counts without significant changes in MCV or MCHC. Opposing to these results, a significant elevation in TLC count was also detected in control positive group (DEN-treated). These results explained the etiological relationship between anemia (normocytic normochromic anemia) and DEN treatment which might be produced as a result of different mechanisms including either bone marrow cells damage or increase osmotic fragility of RBCs and damage of cell membrane (33). furthermore, (34)reported that DEN not only resulted in reduction in RBCs and platelets count but also induced an increase in the TLC count. The reduction in platelets count could be due to either inhibition of bone marrow activity by DEN which consequently decrease its production or increased its consumption(35). On the other hand, elevation in the total leukocytic count could be due to inflammation occurs dur- ing DEN treatment and bioactivation in the experimental animals. SO has a good role in counteracting DEN - hazard effects on the erythrogram by increasing RBCs and $\mathrm{Hb}$ count. SO has antioxidant ability to improve erythrocyte deformability markedly (10).

The liver condition is indirectly examined through the determination of serum ALT, AST, ALP and $\gamma$ GT. This study reported that The elevations of these enzymes could be attributed to their leakage from damaging cell membrane which induced as aresult of several pathological conditions as hepatic cellular injury $(36,37)$. DEN treated group resulted in increase in ALT, AST, ALP and $\gamma \mathrm{GT}$ serum activities which proved hepatic cell damage. These results were reported elsewhere $(38,39)$.In the current experiment treatment with sesame oil caused a significant reduction in ALT, AST, ALP and $\gamma \mathrm{GT}$ activities which indicate significant recovery of hepatic cell function. The hepatoprotective role of sesame oil may be due to its antioxidant active componentas (sesamin, sesamol, sesamolin, andtocopherol). Which reduce ROS production and lipid peroxidation, by this means the membrane permeability was alleviated and the leakage of these enzymes into the blood was minimized (40).

Sesame oil treated group caused a significant reduction in level of blood glucose when compared with DEN treated group as sesame oil contains monounsaturated fatty acids and bioactive compounds which enhanced $\beta$ cells to produce insulin and regulate the blood glucose (40). The fat-soluble lignans (sesamin, sesamolin, and sesamol) help in decreasing of the hepatic oxidative destruction as a result the blood sugar level was reduced (41).

Concerning to evaluation of serum proteins such as albumin and globulin which concern a good criteria for assessing the synthetic function of the liver(42). In the present study it was noticed that the reduction of total protein level indicate diseased and bad health condition(43). This present study showed considerable decrease in blood serum total protein, albumin, and globulin concentrations in rats with DEN induced hepatopathy that lead to severe liver damage correlated with tissue histoarchitecture. When sesame oil was administrated at 
different doses with i.p injection of DEN result in significant elevation in total protein, albumin and globulin concentrations which proved the recovery of synthetic function of the liver, These results agree with $(44,45)$.

DEN injection enhances the oxidative damage through elevation of hepatic MDA and depleted enzymatic (SOD and CAT) and non enzymatic (GSH) antioxidant markers $(46,47)$. ROS have a critical role in the initiation of lipid peroxidation(48). Which produced in high amount as a result of cellular damage (49). generation of ROS and LPO help in initiation of tumorigenesis (50). DEN enhances hepatic oxidative destruction resulted in HCC formation(51). This study agreed with $(46,47)$. The administration of sesame oil resulted in marked decrease in MDA level and elevation in the activities of (SOD, catalase and GSH) when compared with the DEN-treated rats. The antioxidant effect of $\mathrm{SO}$ is due to the non-fat antioxidants content as (sesamol, sesamin, sesamolin and tocopherol (vit E) (52), which protect the cells from oxidative damage.

The histopathological changes in liver tissues caused by DEN revealed the increased percentage of degenerated hepatocytes manifested as areas of perivascular inflammatory infiltrates with diffuse ballooning degeneration, severe ballooning of hepatocytes associated with bile duct and oval cell proliferation. This may be due to the hepatotoxic effect of DEN which causes oxidative stress and liver tissue damage. Hepatic cell degeneration induced by DEN administration is in harmony with those obtained, $(25,53,54)$. Sesame oil administration decreased oxidative damage in HCC rats through reducing production of ROS and LPO leading to significant improvement of hepatic tissue which evidenced as marked decrease in hepatic vacuolation, inflammatory infiltrates, oval cell proliferation and centrolobular necrosis.

Molecular gene expression (CYP2E1 and $B A X)$ are considered important genes expression in cancer. The cytochromes P450 (CYPs) are main enzymes in development and treatment of cancer. They enhance the metabolic activation of several carcinogenic substances as (benzene, $\mathrm{CCL}_{4}$,chloroform, styrene, $\mathrm{N}$-nitrosodimethylamine, NNK)(55). Thus, CYP2E1 might be an essential gene in detection toxicity and carcinogenicity susceptibility to human from environmental and industrial chemicals (54, 56). CYP2E1 is one of CYPs Class one which activated during pre-carcinogens and drugs metabolism. In this study liver of DENtreated rats produced an over expression of $C Y P 2 E 1$ gene opposing to control group results,(57) supported these findings.CYP2E1 has an important role in metabolism and activation a number of chemicals, solvents, cancer producing agents. Sesame oil treated animals showed a significant down regulation in CYP2E1 gene expression when compared with DEN-treated group. Sesame oil has a methylenedioxypheny compounds which are potent inhibitors or inactivators of $C Y P$ isoforms. These compounds could interact with the CYP450 isozymes and affect the drug metabolisms resulting in inhibition in the activity of this gene(58).

$B A X$ is a pro-apoptotic gene that regulates cell death. It is an important indicator of mitochondrial dysfunction and one of the essential pro-apoptotic members of the $\mathrm{Bcl}$-2 family proteins. It manages the apoptosis process within normal and cancer cells. Apoptosis Dysfunction makes the cancer treatment more difficult and helps tumorigenesis to progress. Activation of $B A X$ gene increases permeability of the mitochondrial membrane; result in releasing of apoptotic factor cytochrome $c$ which causes cancer cell death. In the current study DENtreated rats showed significant down regulation in the expression of $B A X$ gene when compared with control negative group. DEN inhibits apoptosis, promoting the proliferation of cancer cell and increase cell survival. These results agreed with(59).Sesame oil treated rats revealed a significant over expression of $B A X$ gene in comparing with DEN-treated animals as Sesame oil enhanced cytochrome releasing from mitochondria leading to promote caspase3 cleavage (the initiator- and important caspases in the intrinsic pathway of apoptosis)induce apoptosis (60), which subsequent arrest proliferation of cancer cell and cause death to it. 


\section{Conclusion}

The data in the current study conclusively demonstrated that oral administration of sesame oil exert significant protective effects against DEN induced oxidative and liver damage by increasing host antioxidant defense mechanisms. This could be attributing to the improvement of anemia, decrease in serum liver enzyme activity, reduced the degree of hepatic vacuolation and necrosis of by DEN, down regulation of CYPE21and up regulation of BAX gene which enhance cancer treatment.

\section{References}

1. Tabor E. Hepatocellular carcinoma: global epidemiology, Digestive and Liver Disease 2001; 33(2): 115-7.

2. Alzahrani F A, El-Magd M A, AbdelfattahHassan A, Saleh A A, Saadeldin I M, El-Shetry E S, Badawy A A, Alkarim S. Potential Effect of Exosomes Derived from Cancer Stem Cells and MSCs on Progression of DEN-Induced HCC in Rats, Stem Cells International 2018; 2018: 17 https://doi.org/10.1155/2018/8058979.

3. Jemal A, Siegel R, Ward E, Hao Y, Xu J, Thun M J. Cancer statistics, 2009, CA: a cancer journal for clinicians 2009; 59(4): 225-49.

4. Ferlay J, Shin H R, Bray F, Forman D, Mathers C, Parkin D M. Estimates of worldwide burden of cancer in 2008: GLOBOCAN 2008, International journal of cancer 2010; 127(12): 2893917.

5. Ciemniak A. A comparison of N-nitrosodimethylamine contents in selected meat products, Roczniki Panstwowego Zakladu Higieny 2006; 57(4): 341-6.

6. Al-Rejaie S S, Aleisa A M, Al-Yahya A A, Bakheet S A, Alsheikh A, Fatani A G, Al-Shabanah O A, Sayed-Ahmed M M. Progression of diethylnitrosamine-induced hepatic carcinogenesis in carnitine-depleted rats, World journal of gastroenterology: WJG 2009; 15(11): 1373.

7. Elkeiy M, Khamis A, El-Gamal M, Abo Gazia M, Zalat Z, El-Magd M. Chitosan nanoparticles from Artemia salina inhibit progression of hepatocellular carcinoma in vitro and in vivo, Environ Sci Pollut Res Int. doi: 10.1007/s11356-018-3339-6 2018.

8. Valko M, Rhodes C, Moncol J, Izakovic M, Mazur M. Free radicals, metals and antioxidants in oxidative stress-induced cancer, Chemico-biological interactions 2006; 160(1): 1-40.
9. Chandrasekaran V R M, Wan C-H, Liu L-L, Hsu D-Z, Liu M-Y. Effect of sesame oil against acetaminophen-induced acute oxidative hepatic damage in rats, Shock 2008; 30(2): 217-21.

10. Abdel-Daim M M, Taha R, Ghazy E W, ElSayed Y S. Synergistic ameliorative effects of sesame oil and alpha-lipoic acid against subacute diazinon toxicity in rats: hematological, biochemical, and antioxidant studies, Canadian journal of physiology and pharmacology 2015; 94(1): 81-8.

11. Sayed-Ahmed M M, Aleisa A M, Al-Rejaie S S, Al-Yahya A A, Al-Shabanah O A, Hafez M M, Nagi M N. Thymoquinone attenuates diethylnitrosamine induction of hepatic carcinogenesis through antioxidant signaling, Oxidative medicine and cellular longevity 2010; 3(4): 254-61.

12. Saleem M T, Chetty M C, Kavimani S. Antioxidants and tumor necrosis factor alpha-inhibiting activity of sesame oil against doxorubicin-induced cardiotoxicity, Therapeutic advances in cardiovascular disease 2014; 8(1): 4-11.

13. Abdelhady D H, El-Magd M A, Elbialy Z I, Saleh A A. Bromuconazole-induced hepatotoxicity is accompanied by upregulation of PXR/CYP3A1 and downregulation of CAR/CYP2B1 gene expression, Toxicol Mech Methods 2017; 27(7): 544-50.

14. Adnan F, Sadiq M, Jehangir A. Anti-hyperlipidemic effect of Acacia honey (desi kikar) in cholesterol-diet induced hyperlipidemia in rats, Biomedica 2011; 27(13): 62-7.

15. Belfield A, Goldberg D. Colorimetric determination of alkaline phosphatase activity, Enzyme 1971; 12(5): 561-8.

16. Burtis C A, Ashwood E R, Bruns D E, Tietz textbook of clinical chemistry and molecular diagnostics-e-book, Elsevier Health Sciences2012.

17. Nagy F M, Taha N M, Mandour A E W A, Lebda M A, Hashem A S. The Biochemical Effects of Berberine on Hyperlipidemia and Insulin Resistance in Rats Fed High Fat Diet, Alexandria Journal for Veterinary Sciences 2016; 51(2): 142-7.

18. Esterbauer H, Cheeseman K, Dianzani M, Poli G, Slater T. Separation and characterization of the aldehydic products of lipid peroxidation stimulated by ADP-Fe2+ in rat liver microsomes, Biochemical Journal 1982; 208(1):129-35.

19. Sinha A K. Colorimetric assay of catalase, Analytical biochemistry 1972; 47(2): 389-94.

20. Packer L. Antioxidant action of carotenoids in vitro and in vivo and protection against oxidation of human low-density lipoproteins, Annals of the New York Academy of Sciences 1993; 691(1): 4860. 
21. Beutler E. Improved method for the determination of blood glutathione, J. lab. clin. Med. 1963; 61: 882--8.

22. Glazer A N, Packer L, Oxygen Radicals in Biological Systems: Oxygen radicals and antioxidants, Academic Press 1990.

23. McDonald J, Pilgram T. Nuclear expression of p53, p21 and cyclin D1 is increased in bronchioloalveolar carcinoma, Histopathology 1999; 34(5): 439-46.

24. El-Magd M A, Abbas H E, El-kattawy A M, Mokhbatly A. Novel polymorphisms of the IGF1R gene and their association with average daily gain in Egyptian buffalo (Bubalus bubalis), Domestic animal endocrinology 2013; 45(2): 105-10.

25. Chen B, Ning M, Yang G. Effect of paeonol on antioxidant and immune regulatory activity in hepatocellular carcinoma rats, Molecules 2012; 17(4): 4672-83.

26. Valko M, Izakovic M, Mazur M, Rhodes C J, Telser J. Role of oxygen radicals in DNA damage and cancer incidence, Molecular and cellular biochemistry 2004; 266(1-2): 37-56.

27. Hassan H A, Serag H M, Abdel-Hamid N M, Amr M M. Synergistic curative effect of chicory extract and cisplatin against thioacetamide-induced hepatocellular carcinoma, Hepatoma Res 2015; 1: 147-54.

28. Chakraborty T, Chatterjee A, Rana A, Dhachinamoorthi D, Kumar A, Chatterjee M. Carcinogen-induced early molecular events and its implication in the initiation of chemical hepatocarcinogenesis in rats: Chemopreventive role of vanadium on this process, Biochimica et Biophysica Acta (BBA)-Molecular Basis of Disease 2007; 1772(1): $48-59$.

29. Verna L, Whysner J, Williams G M. N-nitrosodiethylamine mechanistic data and risk assessment: bioactivation, DNA-adduct formation, mutagenicity, and tumor initiation, Pharmacology \& therapeutics 1996; 71(1-2): 57-81.

30. Ramakrishnan G, Raghavendran H R B, Vinodhkumar R, Devaki T. Suppression of N-nitrosodiethylamine induced hepatocarcinogenesis by silymarin in rats, Chemico-biological interactions 2006; 161(2): 104-14.

31. Kinghorn A D, Su B-N, Jang D S, Chang L C, Lee D, Gu J-Q, Carcache-Blanco E J, Pawlus A D, Lee S K, Park E J. Natural inhibitors of carcinogenesis, Planta medica 2004; 70(08): 691-705.

32. Liju V B, Jeena K, Kuttan R. Acute and subchronic toxicity as well as mutagenic evaluation of essential oil from turmeric (Curcuma longa L), Food and chemical toxicology 2013; 53: 52-61.
33. Yuan G, Dai S, Yin Z, Lu H, Jia R, Xu J, Song X, Li L, Shu Y, Zhao X. Toxicological assessment of combined lead and cadmium: acute and subchronic toxicity study in rats, Food and chemical toxicology 2014; 65: 260-68.

34. Marković S D, Žižić J B, Đačić D S, Obradović A D, Ćurčić M G, Cvetković D M, Đorđević N Z, Ognjanović B I, Štajn A. Alteration of oxidative stress parameters in red blood cells of rats after chronic in vivo treatment with cisplatin and selenium, Archives of Biological Sciences 2011; 63(4): 991-9.

35. Sirag H. Biochemical and hematological studies for the protective effect of oyster mushroom (Pleurotus ostreatus) against glycerol-induced acute renal failure in rats, J Biol Sci 2009; 9(7):746-52.

36. Kadir F A, Kassim N M, Abdulla M A, Yehye W A. Hepatoprotective role of ethanolic extract of Vitex negundo in thioacetamide-induced liver fibrosis in male rats, Evidence-Based Complementary and Alternative Medicine 2013; 2013.

37. Nyblom H, Berggren U, Balldin J, Olsson R. High AST/ALT ratio may indicate advanced alcoholic liver disease rather than heavy drinking, Alcohol and alcoholism 2004; 39(4): 336-9.

38. Hemieda F, Serag H, El-Baz E, Ramadan S. Therapeutic efficacy of licorice and/or cisplatin against diethylnitrosamine and carbon tetrachloride-induced hepatocellular carcinoma in rats, J Am Sci 2016; 12: 10-19.

39. Kumar V R. Protective potential of Hesperidin against Diethylnitrosamine induced Hepatocarcinogenesis in rats, Journal of Drug Discovery and Therapeutics 2014; 2.(15)

40. Hsu D-Z, Su S-B, Chien S-P, Chiang P-J, Li Y-H, Lo Y-J, Liu M-Y. Effect of sesame oil on oxidative-stress-associated renal injury in endotoxemic rats: involvement of nitric oxide and proinflammatory cytokines, Shock 2005; 24(3): 276-80.

41. Ramesh B, Saravanan R, Pugalendi K. Influence of sesame oil on blood glucose, lipid peroxidation, and antioxidant status in streptozotocin diabetic rats, Journal of medicinal food 2005; 8(3): 377-81.

42. Yakubu M T, Bilbis L S, Lawal M, Akanji M A. Evaluation of selected parameters of rat liver and kidney function following repeated administration of yohimbine, Biokemistri 2003; 15(2): 50-6.

43. Ibrahim S S, Nassar N N. Diallyl sulfide protects against $\mathrm{N}$-nitrosodiethylamine-induced liver tumorigenesis: role of aldose reductase, World Journal of Gastroenterology: WJG 2008; 14(40): 6145. 
44. Andriţoiu C V, Andriţoiu V, Cuciureanu M, Nica-Badea D, Bibire N, Popa M. Effect of apitherapy products against carbon tetrachloride-induced toxicity in Wistar rats, Romanian journal of morphology and embryology $=$ Revue roumaine de morphologie et embryologie 2014; 55(3): 835-47.

45. Mansour H H, Hafez H F, Fahmy N M. Silymarin modulates cisplatin-induced oxidative stress and hepatotoxicity in rats, Journal of biochemistry and molecular biology 2006; 39(6): 65662.

46. Zhang C-L, Zeng T, Zhao X-L, Yu L-H, Zhu Z-P, Xie K-Q. Protective effects of garlic oil on hepatocarcinoma induced by $\mathrm{N}$-nitrosodiethylamine in rats, International journal of biological sciences 2012; 8(3): 363-7.

47. Singh R, Sharma J, Goyal P. Prophylactic role of Averrhoa carambola (star fruit) extract against chemically induced hepatocellular carcinoma in Swiss albino mice, Advances in pharmacological sciences 2014; 2014.

48. Droge W. Free radicals in the physiological control of cell function, Physiological reviews 2002; 82(1): 47-95.

49. Valko M, Leibfritz D, Moncol J, Cronin M T, Mazur M, Telser J. Free radicals and antioxidants in normal physiological functions and human disease, The international journal of biochemistry \& cell biology 2007; 39(1): 44-84.

50 . Kensler T W, Trush M A. Role of oxygen radicals in tumor promotion, Environmental mutagenesis 1984; 6(4): 593-616.

51. Qi Y, Chen X, Chan C y, Li D, Yuan C, Yu F, Lin M C, Yew D T, Kung H F, Lai L. Two-dimensional differential gel electrophoresis/analysis of diethylnitrosamine induced rat hepatocellular carcinoma, International journal of cancer 2008; 122(12): 2682-8.
52. Fukuda Y. Food chemical studies on the antioxidants in sesame seed, Nippon Shokuhin Kogyo Gakkaishi 1990; 37(6): 484-92.

53. Imamoto R, Okano J I, Sawada S, Fujise Y, Abe R, Murawaki Y. Null anticarcinogenic effect of silymarin on diethylnitrosamine-induced hepatocarcinogenesis in rats, Experimental and therapeutic medicine 2014; 7(1): 31-8.

54. Rajan B, Ravikumar R, Premkumar T, Devaki T. Carvacrol attenuates N-nitrosodiethylamine induced liver injury in experimental Wistar rats, Food Science and Human Wellness 2015; 4(2): 66-74.

55. Rodriguez-Antona C, Ingelman-Sundberg $M$. Cytochrome P450 pharmacogenetics and cancer, Oncogene 2006; 25(11): 1679-84.

56. Rooseboom M, Commandeur J N, Vermeulen N P. Enzyme-catalyzed activation of anticancer prodrugs, Pharmacological reviews 2004; 56(1): 53-102.

57. Oyama T, Kagawa N, Kunugita N, Kitagawa K, Ogawa M, Yamaguchi T, Suzuki R, Kinaga T, Yashima Y, Ozaki S. Expression of cytochrome $\mathrm{P} 450$ in tumor tissues and its association with cancer development, Front Biosci 2004; 9: 1967-76.

58. Gokbulut C. Sesame oil: potential interaction with P450 isozymes, Journal of Pharmacology and Toxicology 2010; 5(8): 469-72.

59. Zhu H-Z, Ruan Y-B, Wu Z-B, Zhang C-M. Kupffer cell and apoptosis in experimental HCC, World journal of gastroenterology 2000; 6(3): 405.

60. Hsieh P F, Hou C-W, Yao P-W, Wu S-P, Peng Y-F, Shen M-L, Lin C-H, Chao Y-Y, Chang $\mathrm{M}-\mathrm{H}$, Jeng K-C. Sesamin ameliorates oxidative stress and mortality in kainic acid-induced status epilepticus by inhibition of MAPK and COX-2 activation, Journal of neuroinflammation 2011; 8(1): 57. 